Check for updates

Cite this: RSC Adv., 2020, 10, 27305

Received 9th April 2020

Accepted 14th July 2020

DOI: $10.1039 / \mathrm{d} 0 \mathrm{ra03210 \textrm {g }}$

rsc.li/rsc-advances

\section{Dual stimuli-responsive polyphosphazene-based molecular gates for controlled drug delivery in lung cancer cells $\dagger$}

\author{
Yolanda Salinas, (D) *ab Michael Kneidinger, ${ }^{a}$ Cristina Fornaguera, (iD ${ }^{c}$ \\ Salvador Borrós, (D) Oliver Brüggemann (iD a and lan Teasdale (D) ab
}

\begin{abstract}
A switchable silane derived stimuli-responsive bottle-brush polyphosphazene (PPz) was prepared and attached to the surface of mesoporous silica nanoparticles (MSNs). The hybrid polymer with PEG-like Jeffamine ${ }^{\circledR}$ M-2005 side-arms undergo conformational changes in response to both $\mathrm{pH}$ and temperature due to its amphiphilic substituents and protonatable main-chain, hence were investigated as a gatekeeper. Safranin $O$ as control fluorophore or the anticancer drug camptothecin (CPT) were encapsulated in the PPz-coated MSNs. At temperatures below the lower critical solution temperature (LCST), the swollen conformation of PPz efficiently blocked the cargo within the pores. However, above the LCST, the PPz collapsed, allowing release of the payload. Additionally, protonation of the polymer backbone at lower $\mathrm{pH}$ values was observed to enhance opening of the pores from the surface of the MSNs and therefore the release of the dye. In vitro studies demonstrated the ability of these nanoparticles loaded with the drug camptothecin to be endocytosed in both models of tumor (A549) and healthy epithelial (BEAS-2B) lung cells. Their accumulation and the release of the chemotherapeutic drug, co-localized within lysosomes, was faster and higher for tumor than for healthy cells, further, the biocompatibility of PPz-gated nanosystem without drug was demonstrated. Tailored dual responsive polyphosphazenes thus represent novel and promising candidates in the construction of future gated mesoporous silica nanocarriers designs for lung cancer-directed treatment.
\end{abstract}

\section{Introduction}

Macromolecular materials can undergo physical changes in response to external stimuli, for example light, $\mathrm{pH}$, temperature, oxidation and magnetic fields. ${ }^{1,2}$ Sometimes referred to as smart or stimuli-responsive polymers, ${ }^{3}$ such materials have wide ranging applications as chemo- and biosensors, ${ }^{4}$ chemomechanical actuators ${ }^{5}$ and controlled release applications. ${ }^{6}$ For the release of bioactives, phosphorus based polymers offer promise due to their capability to be fine-tuned, for their biodegradability and multivalency. ${ }^{7}$ of these, polyphosphazenes $^{\mathbf{8}}$ are quite advanced in biomedical applications, ${ }^{\mathbf{9}, 10}$ with fluorinated derivatives having FDA approval as stent coatings ${ }^{\mathbf{1 1}}$ and vaccine adjuvants in advanced clinical

${ }^{a}$ Institute of Polymer Chemistry (ICP), Johannes Kepler University Linz (JKU), Altenberger Strasse 69, 4040 Linz, Austria. E-mail: yolanda.salinas@jku.at

${ }^{b}$ Linz Institute of Technology (LIT), Johannes Kepler University Linz (JKU), Altenberger Strasse 69, 4040 Linz, Austria

${ }^{c}$ Grup d'Enginyeria de Materials (GEMAT), Institut Quimic de Sarrià (IQS), Universitat Ramon Llull (URL), Via Augusta 390, Barcelona, 08017, Spain

$\dagger$ Electronic supplementary information (ESI) available: Synthesis reaction of PPz; LCST determination of Jeff. 2005; further characterization of the nanomaterials; UV-Vis spectra from SAF released; cell uptake studies up to $24 \mathrm{~h}$. See DOI: 10.1039/d0ra03210g trials. $^{\text {12,13 }}$ Thermoresponsive polyphosphazenes have been extensively investigated, in particular for their use as thermosensitive injectable hydrogels, with, among others, delivery or siRNA for gene silencing, stem cell delivery ${ }^{\mathbf{1 4}}$ and combinatorial cancer therapy. ${ }^{15}$ Due to a widely observed phenomenon for amphiphilic polymers, ${ }^{\mathbf{1 6}, 17}$ thermoresponsive polymers commonly possess a lower critical solution temperature (LCST) in aqueous solutions, above which the macromolecules collapse, followed often by agglomeration and/or gelation. ${ }^{17} \mathrm{On}$ surfaces the macromolecules collapse, ${ }^{18}$ for example to control fuel access to micromotors ${ }^{19}$ or to modulate cell adhesion and detachment, facilitating fabrication of cell sheets. ${ }^{20}$ In this work, we use Jeffamine-functionalized bottle-brush polyphosphazenes which are reported to have LCSTs which can be tuned to biologically relevant temperatures. ${ }^{21}$ The multivalent nature allows for chemical grafting to surfaces while the amphiphilic character is used to adjust LCST. ${ }^{22}$ Furthermore, since the basic nitrogen atoms in the polyphosphazene backbone become protonated in acidic media, $\mathrm{pH}$ can also be a stimulus, influencing the polymer polarity, LCST and potentially conformation. ${ }^{23}$

The incorporation of this polymer to the surface of mesoporous silica nanoparticles (MSNs) will increase the nanocarriers stability, maximizing the "stealth" features of this novel 
system and reducing opsonization, all potentially prolonging the blood circulation of the material. The very interesting properties of MSNs, such as thermal stability, easy chemical functionalization or rigid framework which prevents premature degradation of the cargo, make them stand out as synthetic platforms in the design of hybrid materials. ${ }^{24}$ Among many applications, gated mesoporous silica nanoparticles have been promoted mainly in biomedicine ${ }^{25,26}$ because these systems are promising candidates for developing new, more efficient and safety improved therapies, setting a precedent in the area of drug delivery. ${ }^{27}$ The external functionalization of the pores with stimuli-responsive hydrophilic polymeric gate-keeper units by easy "click" post-grafting strategy ${ }^{28}$ permits the controlled release upon application of different stimuli while enhancing their stability in aqueous environments. Therefore, we designed and report herein hybrid silica-based nanomaterials containing molecular gates based on polyphosphazene polymer units sensitive to both temperature and $\mathrm{pH}$ to control more precisely the delivery of chemotherapeutics through a selective and reversible "close-opening gate mechanism".

\section{Results and discussion}

\section{1. $\mathrm{pH}$ and temperature responsive nanosystem design and} gated mechanism

A schematic representation of the $\mathrm{pH}$ and thermoresponsive polyphosphazene-based molecular gate nanosystem for controlled drug delivery is shown in Fig. 1. Initially, mesoporous silica nanoparticles (MSNs) were synthesized to act as inorganic carrier following the well-known sol-gel process. For this, the silica precursor tetraethylorthosilicate (TEOS) forms around the cationic surfactant cetyltrimethyl ammonium bromide (CTAB) as pore-template agent under alkaline conditions carried out as reported in literature. ${ }^{29}$ The mesoporous nanoparticles were obtained by calcination at $550{ }^{\circ} \mathrm{C}$ (so called here nanoparticles MSN0).

The empty porous nanoparticles were then loaded with the dye safranin $\mathrm{O}$ as suitable cargo unit. The outer pores surface of the loaded MSNs was functionalized with 3-(azidopropyl)triethoxysilane groups (nanoparticles MSN1-SAF-AZ labelled according to the corresponding loaded cargo) to subsequently be added by a copper catalysed Huisgen cycloaddition reaction $^{\mathbf{2 8 , 3 0}}$ to previously synthetized polyphosphazenes containing Jeffamine ${ }^{\circledR}$ M-2005 and alkyne moieties (polymer called here as $\mathrm{PPz}$ ). The resulting nanoparticles were isolated by centrifugation, washed with water and acetonitrile to remove any residual cargo, possible catalyst traces and ungrafted polymer moieties. A final drying step under vacuum yielded the nanomaterial MSN1-SAF-PPz.

\subsection{Characterization of the gatekeeper polyphosphazene}

A bottle-brush polyphosphazene was prepared containing two different substituents, hydrophilic PEO-PPO- $\mathrm{NH}_{2}$ oligomers (Jeffamine ${ }^{\circledR} \mathrm{M}$-2005) and 2-propynylamine in molar ratios $1: 2$, confirmed by ${ }^{1} \mathrm{H}-\mathrm{NMR}$ spectroscopy (see ESI $\dagger$ ). Initially, a precursor poly(dichloro)phosphazene $\left[\mathrm{NPCl}_{2}\right]_{n}$ with 50
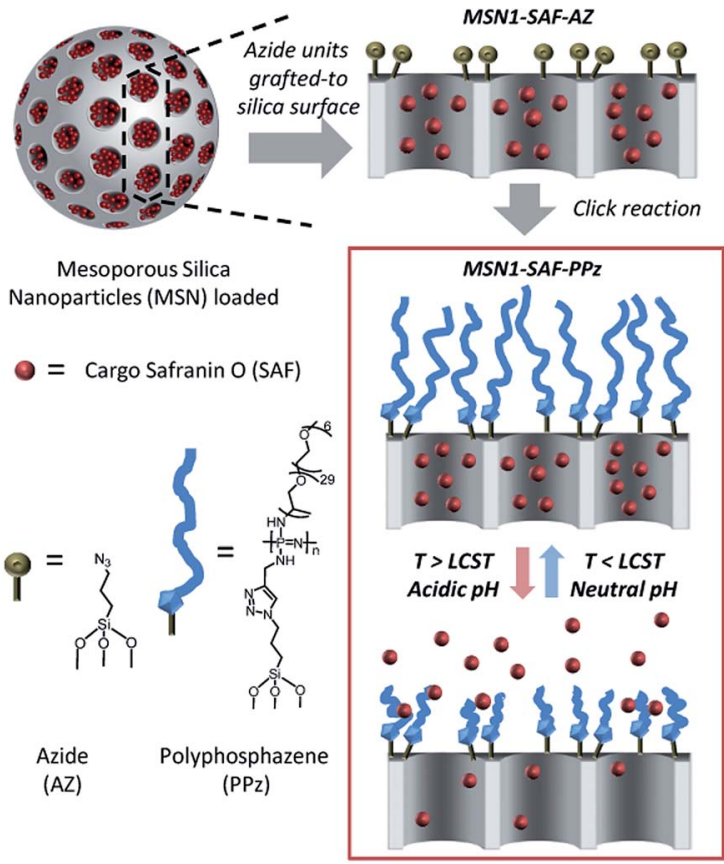

Fig. 1 Schematic illustration of the polymer functionalization on the silica surface and the cargo controlled release mechanism of dual temperature and $\mathrm{pH}$ responsive gated polyphosphazene units (PPz). The material was initially uploaded with safranin $O$ and grafted with azide moieties (MSN1-SAF-AZ) following the attachment of the polymer to the surface of silica mesopores via click chemistry (MSN1-SAF$\mathrm{PPz}$ ). The scheme of PPz shows the simplified structure of the statistically distributed Jeffamine ${ }^{\circledR}$ M-2005 moieties along the polymer backbone ( $n \sim 50$ ). Cargo release occurs by increasing the temperature above LCST of PPz due to collapsing of the polymer and opening the pores.

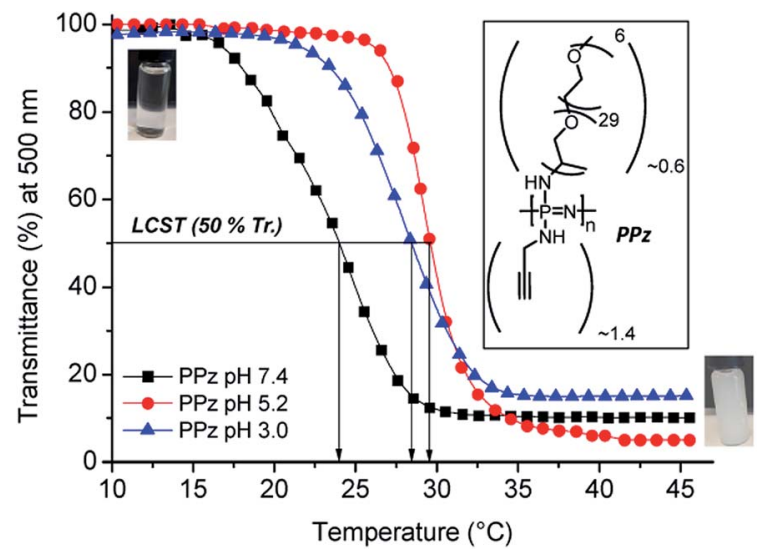

Fig. 2 Lower critical solution temperature (LCST) of Jeffamine ${ }^{\circledR} M$ 2005 and Jeffamine containing polyphosphazene (PPz) $(n \sim 50)$ determined by transmittance measurements with increasing temperature at $500 \mathrm{~nm}$ for $1 \mathrm{mg} \mathrm{mL}^{-1}$ of the polymer in phosphate buffer solution at $\mathrm{pH} 7.4,5.2$ and acidic solution of $\mathrm{pH} 3.0$, inset: chemical structure of polymer PPz and corresponding images of the polymer solution (1 $\mathrm{mg} \mathrm{mL}^{-1}$ ) below (transparent solution) and above LCST (collapsed state and agglomerated polymer chains) at neutral $\mathrm{pH}$. 
repeating units (estimated by ${ }^{31} \mathrm{P}$ NMR, see ESI $\dagger$ ) was prepared via phosphine-mediated living polymerization of $\mathrm{Cl}_{3} \mathrm{P}=\mathrm{N}-$ $\mathrm{SiMe}_{3}$, as reported in the literature. ${ }^{31}$ The chlorine atoms of this precursor were then substituted with 2-propynylamine and with Jeffamine ${ }^{\circledR}$ M-2005 yielding the final polyphosphazene (termed $\mathrm{PPz}$, see structure in Fig. 2 inset).

The LCST of PPz was determined by UV-Vis spectroscopy at different $\mathrm{pH}$ and temperature conditions (Fig. 2). Initially, the inherent thermoresponsive of Jeffamine ${ }^{\circledR}$ M-2005 was measured at neutral and acidic pHs and a negligible increase of $1{ }^{\circ} \mathrm{C}$, in the range of $21-22{ }^{\circ} \mathrm{C}$, from PBS solutions at $\mathrm{pH} 7.4$ to 5.2 (see Fig. SI-2, ESI $\dagger$ ). The same procedure was repeated for $\mathrm{PPz}$, up to $\mathrm{pH}$ 3.0. Interestingly, the PPz showed $\mathrm{pH}$ dependent response, with a shift towards higher temperatures, from 24 to 28-29 ${ }^{\circ} \mathrm{C}$ upon moving from neutral to acidic conditions (LCST determination at $50 \%$ transmittance, see Fig. 2). That was in agreement to the expected overall increase of the hydrophilicity of the polymer due to protonation of the $\mathrm{N}$ atoms from the $\mathrm{PPz}$ backbone at acidic pHs. ${ }^{19}$

\subsection{Characterization of the hybrid nanosystems}

The morphology of the prepared hybrid mesoporous silica nanoparticles was initially determined by transmission electron microscopy (TEM). The TEM micrograph of the mesoporous silica nanoparticles containing the dye and functionalized with azide groups (MSN1-SAF-AZ) showed homogeneous spherical shape and external smooth surface, with sizes below $120 \mathrm{~nm}$. The hexagonal and longitudinal arrangement of regular pores observed was in agreement with similar previously reported MCM-41 type nanoparticles porosity (typical repeated mesopores are shown as black and white stripes in Fig. $3 \mathrm{c}$ ). ${ }^{32}$

In order to confirm this, their hydrodynamic diameter was estimated by dynamic light scattering in aqueous suspension. The data collected in Table 1 was in agreement with the previous microscope images. A negligible difference in hydrodynamic diameter from calcined MSN0 to intermediate nanomaterials MSN1-SAF-AZ was estimated where the nanoparticles kept their size distribution after dye loading and functionalization with azides ( $D_{\mathrm{h}}$ between 108-110 nm). Besides, a higher increase in size of $c a .40 \mathrm{~nm}$ was detected for the polymer functionalized nanomaterial MSN1-SAF-PPz, observed also in the TEM micrograph (see Fig. 3c). Their corresponding polydispersity was slightly higher (see Fig. $3 \mathrm{~b}$ and Table 1 ) for that final nanomaterial. Here, the volume distribution was chosen to show the closer measured scattering from the compared samples. Those parameters changes were directly attributed to a)

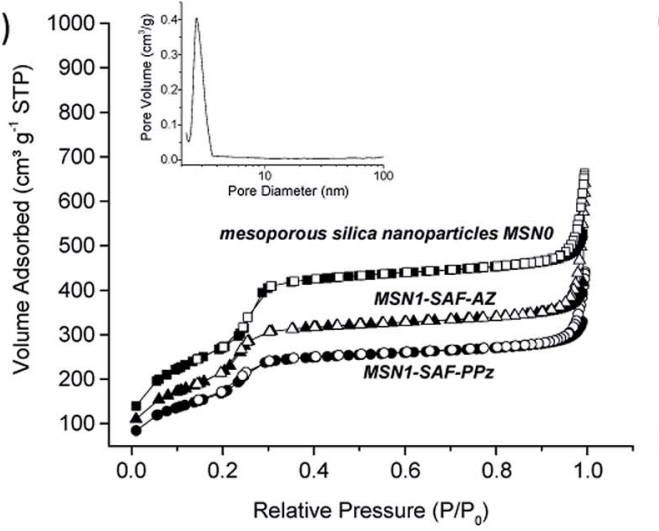

b)

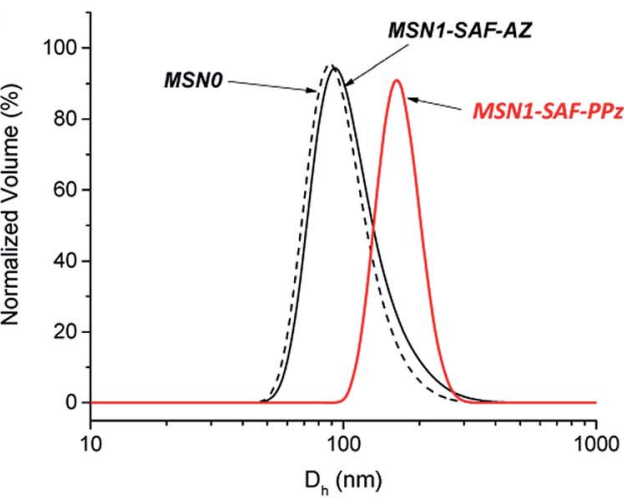

c)

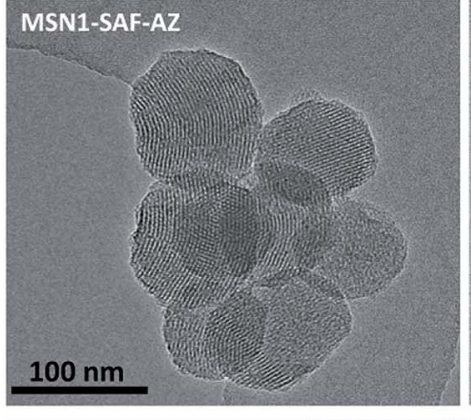

MSN1-SAF-PPZ

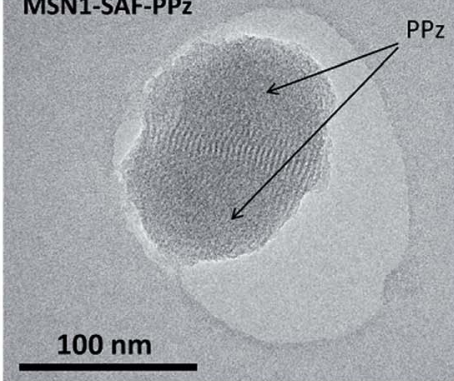

d)
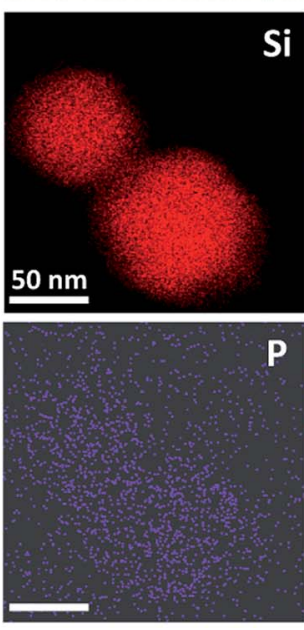

(

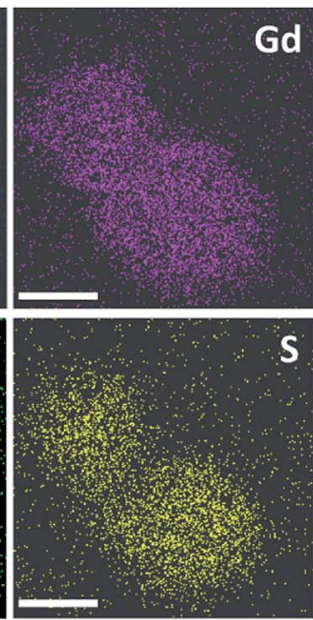

Fig. 3 (a) Nitrogen adsorption-desorption isotherms of materials MSNO, MSN1-SAF-AZ and MSN1-SAF-PPz. Full symbols and empty symbols stand for adsorption and desorption respectively, inset: BJH pore size distribution of MSNO; (b) dynamic light scattering (DLS) measurements (hydrodynamic diameter, $D_{\mathrm{h}}$, via normalized volume) of MSNO, MSN1-SAF-AZ and MSN1-SAF-PPz (1 mg mL $\mathrm{m}^{-1}$ aqueous suspension); (c) TEM images of the safranine-loaded nanoparticles MSN1-SAF-AZ and MSN1-SAF-PPz, where the polymer was located on the surrounding of the silica surface blocking the pores, marked by arrows in the right image. Scale bar: $100 \mathrm{~nm}$; (d) TEM-EDX mapping images of nanoparticles MSN1-SAFPPz stained with Uranyless (uranium-free staining contrast solution). Gd element was used as contrast agent, highly staining the organic parts of the system. Scale bar: $50 \mathrm{~nm}$. 
Table 1 Characterization data of the prepared nanoparticles (BET specific surface values, pore volumes, pore sizes calculated from the $\mathrm{N}_{2}$ adsorption-desorption isotherms, and particle diameter of the nanoparticles)

\begin{tabular}{lllll}
\hline MSNs & $\begin{array}{l}S_{\mathrm{BET}} \\
\mathrm{m}^{2} \mathrm{~g}^{-1}\end{array}$ & $\begin{array}{l}\text { Pore vol. }^{a} \\
\mathrm{~cm}^{3} \mathrm{~g}^{-1}\end{array}$ & $\begin{array}{l}\text { Pore size }^{a} \\
\mathrm{~nm}\end{array}$ & $\begin{array}{l}D_{\mathrm{h}}{ }^{b} \\
\mathrm{~nm}(\mathrm{PdI})\end{array}$ \\
\hline MSN0 & & & & \\
MSN1-SAF-AZ & 768 & 0.93 & 2.9 & $108 \pm 50(0.221)$ \\
MSN1-SAF-PPz & 632 & 0.74 & 2.8 & $110 \pm 38(0.403)$ \\
\end{tabular}

${ }^{a}$ Pore volumes and pore sizes are associated with intraparticles mesopores, estimated by BJH model. ${ }^{b}$ Hydrodynamic diameters of the nanoparticles measured by DLS (average by volume of 6 independent measurements).

the presence of bulky $\mathrm{PPz}$ molecules attached to the silica nanoparticles surface.

To confirm this assumption, the material MSN1-SAF-PPz was analyzed by energy-disperse X-ray spectroscopy (TEM-EDX) and a substantial coverage of PPz attached to the outer silica surface was clearly visualized (see TEM image of MSN1-SAF-PPz in Fig. 3c were the polymer is marked by arrows). Remarkably, all the expected elements ( $\mathrm{Si}, \mathrm{O}, \mathrm{Gd}, \mathrm{P}, \mathrm{N}$ and $\mathrm{S}$ ) were well distributed and localized on the mesoporous surface (see mapping images in Fig. 3d). For the measurement, a uraniumfree staining contrast solution containing Gd, among other non-radioactive elements, was used to enhance the organic side contrast against the inorganic silica-based nanoparticles. It is worth noting that although the polymer was grafted via coppercatalysed click reaction, no characteristic signal from this metal was detected in the final nanomaterial, an important consideration for the bioapplication of the nanosystems.

Additionally, the characteristic structural properties of the hybrid nanoparticles were characterized after each loading and functionalization steps. Surface area, pore volume and pore size were obtained from their corresponding $\mathrm{N}_{2}$ adsorptiondesorption analysis (see structural parameters in Table 1). Typically, isotherms type IV presenting an adsorption step at 0.1-0.3 $P / P_{0}$ were obtained (see isotherms related to safraninloaded and PPz-functionalized nanoparticles compared to the calcined control material in Fig. 3a). MSN0 showed typical structural parameters of mesoporous silica nanoparticles type MCM-41 (surface area of $c a .1000 \mathrm{~m}^{2} \mathrm{~g}^{-1}$, pore volume of 0.93 $\mathrm{cm}^{3} \mathrm{~g}^{-1}$, and pore size of $2.9 \mathrm{~nm}$ ). In comparison, the nanomaterials MSN1-SAF-AZ presented smaller surface areas and pore volumes $\left(762 \mathrm{~m}^{2} \mathrm{~g}^{-1}\right.$ and $\left.0.74 \mathrm{~cm}^{3} \mathrm{~g}^{-1}\right)$ calculated by BET and BJH models. These features were consistent with previous reported materials with partially filled mesopores and functionalized surfaces with short moieties, ${ }^{33,34}$ such as the here used azide moieties. Similar pore sizes $(2.8 \mathrm{~nm})$ compared with bare calcined MSN0 was obtained for this intermediate material (see BJH pore size distribution curve in Fig. 3a). As expected, the final nanomaterials functionalized with polyphosphazene (MSN1-SAF-PPz) showed a characteristic decrease in surface area, $c a .100 \mathrm{~m}^{2} \mathrm{~g}^{-1}$, which further confirms, along with above previous characterization results, the presence of grafted polymer on the external silica surface. The pore size values for the MSN1-SAF-PPz nanomaterial was not considered (not shown in the table) due to classic analysis miscalculations in fully closed pores. ${ }^{34}$

In a further step, the content of polymer (PPz) and cargo (SAF) was determined by thermogravimetric analysis (see Fig. SI-4a in ESI†). A weight loss assigned to the cargo and the azide moieties for materials MSN1-SAF-AZ was $4.48 \%$ (in agreement with the loss of surface area), and $10.33 \%$ organic weight loss was associated with the polymer in the nanomaterial MSN1-SAF-PPz, and in comparison with calcined MSN0. These contents were similar to other gated mesoporous silica nanocarriers reported in literature. ${ }^{35}$ Moreover, the $\zeta$ potential measurements of the nanoparticles provided further information about the proper functionalization at each
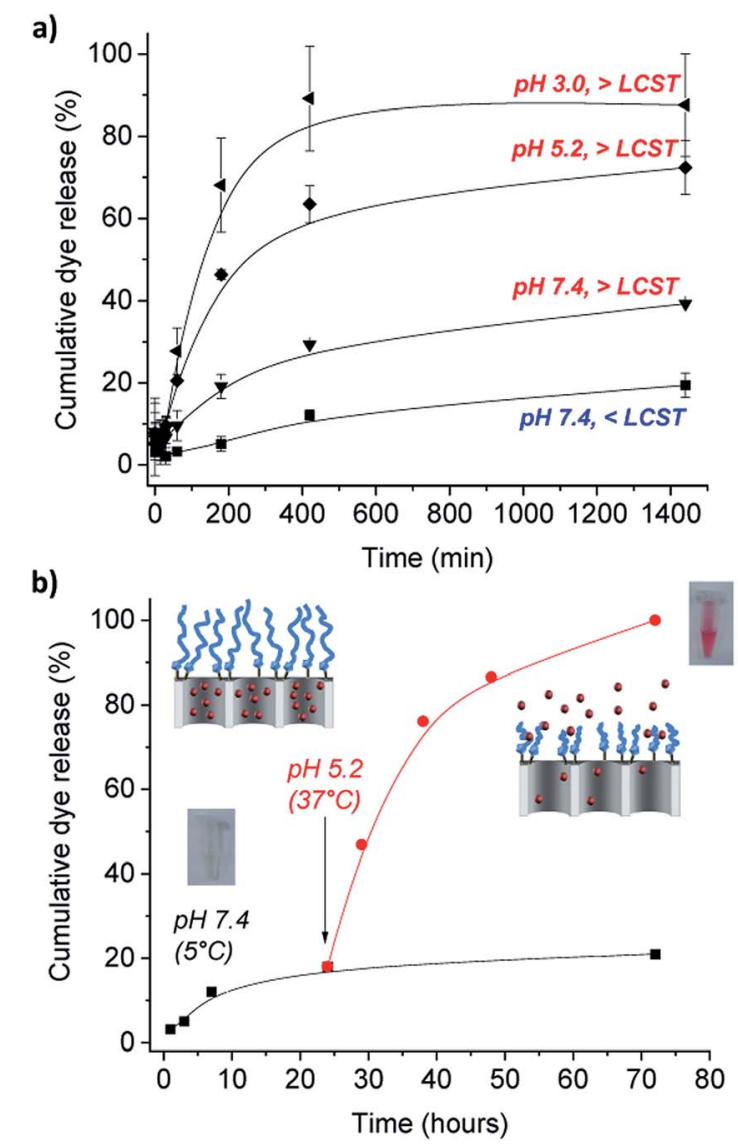

Fig. 4 Cumulative release profiles of (a) safranin $\mathrm{O}$ (SAF) from PBS suspensions of MSN1-SAF-PPz nanoparticles at $\mathrm{pH} 7.4$ (dye absorbance measured at $520 \mathrm{~nm})$ below $\left(\angle \mathrm{LCST}=5^{\circ} \mathrm{C}\right)$ and above $(>\mathrm{LCST}=$ $37^{\circ} \mathrm{C}$ ) the PPz LCST, showing the temperature effect, and release profiles at acidic pHs 5.2 and 3.0 above the LCST (at $37^{\circ} \mathrm{C}$ ) of the dual $\mathrm{pH}$ and temperature responsive gates based on Jeffamine $\AA \mathrm{M}-2005$ derived polyphosphazene (PPz) functionalized on the silica surface. Error bars expressed as $\sigma$ from three independent experiments; (b) cumulative partial dye release from PBS suspensions of MSN1-SAFPPz at cold and neutral conditions for $24 \mathrm{~h}$ and suddenly acidic decrease of $\mathrm{pH}$ and temperature rise above $\mathrm{LCST}_{\mathrm{PPz}}$, at $37^{\circ} \mathrm{C}$, for $48 \mathrm{~h}$ more. Inset: colourless dye release solution collected after of 24 hours at $\mathrm{pH} 7.4$ and pink solution from the dye released at after 48 hours at $\mathrm{pH}$ 5.2. 
preparation step. As expected, the surface properties of the undecorated MSN0 commonly covered by -OH groups was highly negative $(-48 \mathrm{mV})$ and in agreement with this type of nanoparticles. ${ }^{19}$ Similarly, the nanoparticles loaded with azide exhibited a positive increase of the $\zeta$-potential which may be due to the effective grafting step. Surprisingly, after the polymer grafting step the surface charge was not significantly affected. In general, the $\mathrm{PPz}$ improved the dispersion of these silicabased nanocarriers over time, observed during the samples preparation in aqueous solution.

\subsection{Cargo delivery from the dual temperature and $\mathrm{pH}$ responsive hybrid nanosystem}

The dual gate-like behavior of the nanoparticles MSN1-SAF-PPz was studied by following the release of the cargo (safranin $\mathrm{O}$ ) under different conditions of temperature and $\mathrm{pH}$. Initially, in order to study the thermoresponsive role of the Jeffamine-based polyphosphazene on the gate nanosystem, the dye release from MSN1-SAF-PPz was carried out at cold temperatures (at $5{ }^{\circ} \mathrm{C}$, below $\mathrm{LCST}_{\mathrm{PPz}}$ ) and around human body temperature (at $37^{\circ} \mathrm{C}$, above LCST $_{\mathrm{PPz}}$ ), both under neutral $\mathrm{pH} 7.4$ conditions, simulating physiological blood $\mathrm{pH}$. The release studies were monitored for $24 \mathrm{~h}$ (1440 min).

Of importance was also the performance of the nanomaterial in acidic conditions to simulate the cells internal lysosomal $\mathrm{pH}$ medium. Following the same procedure that with temperature changes, the $\mathrm{pH}$ effect was assessed by performing the release studies in phosphate buffer solutions at slightly acidic pH 5.2, typically from late endosomes and also of tumor microenvironments, and at more acidic aqueous solution (prepared at $\mathrm{pH}$ 3.0). ${ }^{36}$ An obvious marked different response was observed from the release profiles showed in Fig. 4a. At neutral pH (which is typical from healthy organs) and temperatures below PPz LCST showed the lowest amount of released cargo ( $c a$. 10 after $7 \mathrm{~h}$ ), as the molecular gates are effectively closed due to the expanded conformation of the PPz. Upon increasing the temperature to above the LCST, release was increased to a modest $27 \%$, due to collapse of the $\mathrm{PPz}$ on the MSN surface. However, a much faster dye release was observed when both effects of $\mathrm{pH}$ and temperature were involved, yielding to a cumulative dye released of 58 and $82 \%$ after $7 \mathrm{~h}$ that kept steady after $24 \mathrm{~h}$ of $72 \%$ and $88 \%$ cargo release measured under acidic conditions for $\mathrm{pH}$ 5.2, and pH 3.0, at above body temperatures (see complete UV-Vis spectra from dye released in ESI, Fig. SI-5 $\dagger$ ). The faster cargo release with the higher temperatures and lower pHs is caused by collapsing of the polymer attached to the silica surface unblocking the pores. While polyphosphazenes are known to degrade at low $\mathrm{pH}$ values over a period of hours or days, ${ }^{21}$ the rapid release of dye (in the first minutes) observed cannot be explained by this. It is however known that polyaminophosphazenes become highly protonated and hence, cationic at lower $\mathrm{pH}$ values ${ }^{23,37}$ and it is possible that this behavior induces conformational changes in the polymer, leading to the clearly detected increased release. Alternatively, it is possible that the positive charge of the $\mathrm{PPz}$ at lower $\mathrm{pH}$ enhances expulsion of the charged dye from the pore. Future studies will be required to confirm this mechanism.

Furthermore, this potential close-open gate mechanism of the hybrid nanomaterial was investigated by suddenly changing the conditions of $\mathrm{pH}$ and temperature, and following the partial release studies of the dye from the pores (Fig. 4b). Similarly, a poor release was detected at neutral $\mathrm{pH}$ and cold temperatures for $24 \mathrm{~h}$, assuming the gate is closed due to the stretched confirmation of the polymer under these conditions (see Fig. 4b). A marked dye release was immediately detected after 48 more hours at $\mathrm{pH} 5.2$ and $37{ }^{\circ} \mathrm{C}$, and easily observed by the naked-eye (see inset images of the release cargo in Fig. 4b). This result was in agreement with the previous triggered response of the functionalized MSN1-SAF-PPz at acidic conditions and temperatures above its LCST (here at $37^{\circ} \mathrm{C}$ ). Significantly, the ability to minimize uncontrolled release doses for future

a)

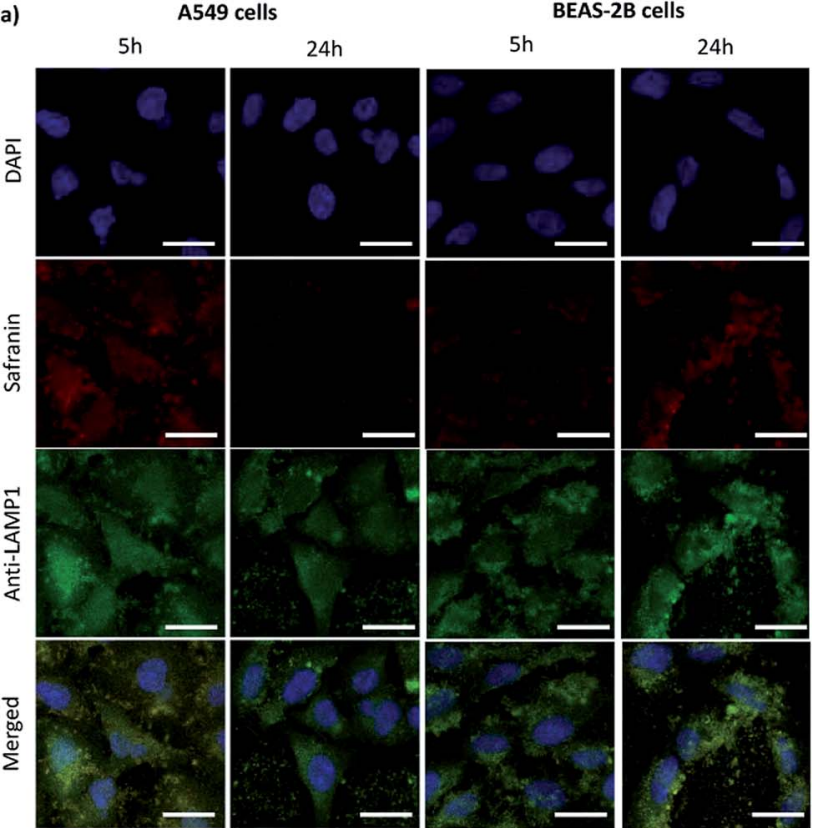

b)

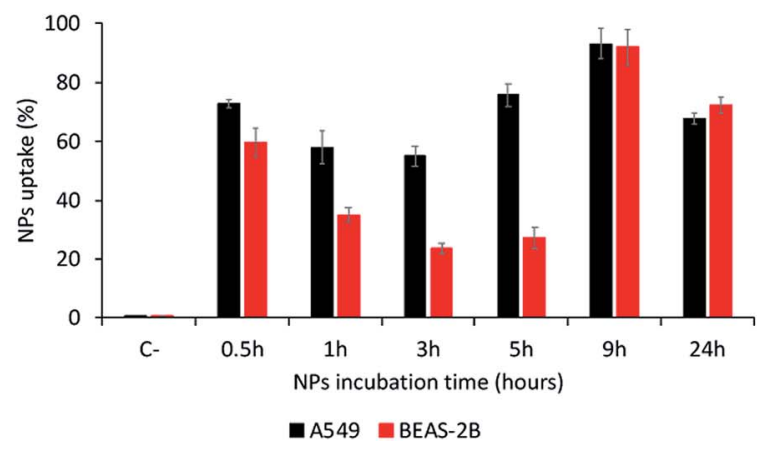

Fig. 5 Uptake study of MSN1-SAF-PPz in tumor (A549) and epithelia (BEAS-2B) lung model cells. (a) Qualitative study by confocal micrographies of nanoparticles after their incubation during short ( $5 \mathrm{~h}$ ) and long ( $24 \mathrm{~h}$ ) times with cells. Blue signal: nuclei staining by DAPI; red signal: safranin; green signal: lysosomes labelling using anti-LAMP1 antibody. Scale bar $=25 \mu \mathrm{m}$. (b) Quantitative study by flow cytometry of MSN1-SAF-PPz uptake in model cells by quantifying safranin. 
biological applications was solved here by using the gated nanomaterials, which progressive release profile over longer periods of time (up to $72 \mathrm{~h}$ ) was demonstrated (see Fig. 4b, pH 7.4).

It is worthy to remark the advantages of this $\mathrm{pH}$ and temperature controlled release in terms of safety. Although the release studies were performed with the dye to facilitate the experimental set up, for lung tumor therapies, a chemotherapeutic drug such as camptothecin will be encapsulated. As it is widely known, the main problem of chemotherapy is the production of side effects due to the systemic biodistribution of the drug. Although our nanoparticles are not actively vectored to tumors, thanks to the enhanced permeability and retention effect, they will be preferentially accumulated in tumor microenvironment. Moreover, since the release of the drug will only take place upon $\mathrm{pH}$ decrease, both factors will contribute to the decrease of the side effects that will enable the increase of the administered dose, thus allowing the efficacy of the treatment.

Therefore, after having demonstrated the well performing dual responsive behavior of the prepared nanoparticles functionalized with $\mathrm{PPz}$ and loaded dye, the application for therapeutic delivering purposes within cancer cells was attempted. For this, a similar nanomaterial but loaded with the chemotherapeutic drug camptothecin (CPT), MSN2-CPT-PPz, was prepared and tested directly on models of healthy and tumor lung cells. This selected payload is a well-known chemotherapeutic agent whose hydrophobic character makes this drug difficult to use. Hence, the possibility to transport it within the pores of mesoporous silica nanoparticles can decrease its solubility problems in water, ${ }^{38}$ while its selective intracellular distribution by means of the stimuli-responsive polyphosphazene gatekeepers could contribute strongly to avoid further unwanted side effects. This new material called MSN2CPT-PPz showed similar features than its partner loaded with safranin O. The nanomaterial MSN2-CPT-PPz presented similar surface areas and pore volumes $\left(451 \mathrm{~m}^{2} \mathrm{~g}^{-1}\right.$ and $0.31 \mathrm{~cm}^{3} \mathrm{~g}^{-1}$, (see corresponding $\mathrm{N}_{2}$ adsorption-desorption isotherms and $\mathrm{BJH}$ pore size distribution curves for this material in Fig SI-3, ESI $\dagger$ ). The content of drug and polymer was also determined by thermogravimetric analysis (see TGA spectra in Fig. SI-4 in ESI $\dagger$ ), amounted to similar functionalization of polymer on the silica surface (ca. 12\%), but higher cargo loading (ca. 28\%) in comparison to MSN1-SAF-PPz, but still within the loadings orders reported in literature. ${ }^{34,35}$ That difference between uploading could be attributed to the different hydrophobic character of the selected cargo molecules which may change the extent of incorporation within the mesopores during the uploading process.

\subsection{Cargo delivery from the responsive hybrid nanosystem inside intracellular media}

Nanoparticles MSN1-SAF-PPz were selected as models for the study of their internalization in models of lung cancer cells (A549), as target cells, and of lung epithelial cells (BEAS-2B), as non-target cells. These responsive hybrid nanosystems were in vitro incubated with both cell lines, during different times, to determine a kinetics of the cell internalization and their uptake was studied by confocal analysis (qualitatively) as well as for flow cytometry analysis (quantitatively). As shown in Fig. 5a (also complete times for A549 cells shown in Fig. SI-7† and for BEAS-2B cells in Fig. SI-8†), safranin uptake took place for both cell lines, indicating that MSN1-SAF-PPz nanoparticles were able to penetrate tumor and healthy cells. However, while the uptake was very fast for A549 cells, achieving around $60 \%$ of cells with internalized nanoparticles at all time-points studied (Fig. 5b), for BEAS-2B it took around $9 \mathrm{~h}$ to achieve a marked uptake, of around $80 \%$. It is noteworthy to remark that at very short incubation-time points, the uptake seems very high for both cell lines tested, according to cytometry data. However, these results could be attributed to an attachment of the nanoparticles on the cell surface, specifically for epithelial lung cells, since, at longer times, the percentage of cells that contain safranin internalized decreased notable at medium times. This effect could be also attributed to the rapid elimination of a fraction of the nanoparticles by BEAS-2B cells at intermediate times.

Another factor to be taken into account is the subcellular localization of the internalized nanoparticles. ${ }^{39}$ To study this effect, we added a marker for lysosomes (anti-LAM1 antibody). The accumulation in lysosomes is important for lysosomes targeting, and could also be advantageous in terms of designing novel therapies for potential lysosomal storages diseases. ${ }^{40}$ This could be justified by a rapid intracellular trafficking of the nanoparticles, expected to be endocytosed by cells to achieve the cell uptake. ${ }^{39}$ Relating these results with viability studies, we may suggest that lysosomal accumulation of the cargo could be advantageous in terms of elimination of the materials after their pharmacological activity which could be beneficial in terms of avoiding toxicities caused by accumulation of nanosystems.

Accordingly, our further measurements regarding potential cytotoxicity of the prepared nanoparticles would enable us to confirm that, a part from the nanoparticles being rapidly colocalized within lysosomes, they could represent a promising lung cancer controlled cytotoxic treatment. Camptothecin, being a topoisomerase I inhibitor, is used thanks to its antineoplastic activity as cancer chemotherapeutic drug. However, its use is limited due to the production of severe side effects in healthy growing cells. For this reason, and due to its poor water solubility, its encapsulation in targeted nanocarriers, as here within mesoporous silica nanoparticles, is strongly recommended to enhance future therapies safety. Hence, we studied the cytotoxicity produced in target (A549 lung tumor) and nontarget (BEAS-2B lung epithelial) cells. In addition, we also studied the possible cytotoxicity of bare nanoparticles (MSN3PPz-control) as well as that from camptothecin-loaded nanoparticles (MSN2-CPT-PPz) at different time-points (Fig. 6 shows the most MTT relevant results).

As shown in Fig. 6a-c, MSN2-CPT-PPz produced a concentration and time-dependent toxicity in A549 lung tumor model cells. In addition, healthy epithelial lung cell mortality was lower at all time points and in all concentrations tested, as compared with lung cancer cells, which enables us to confirm 

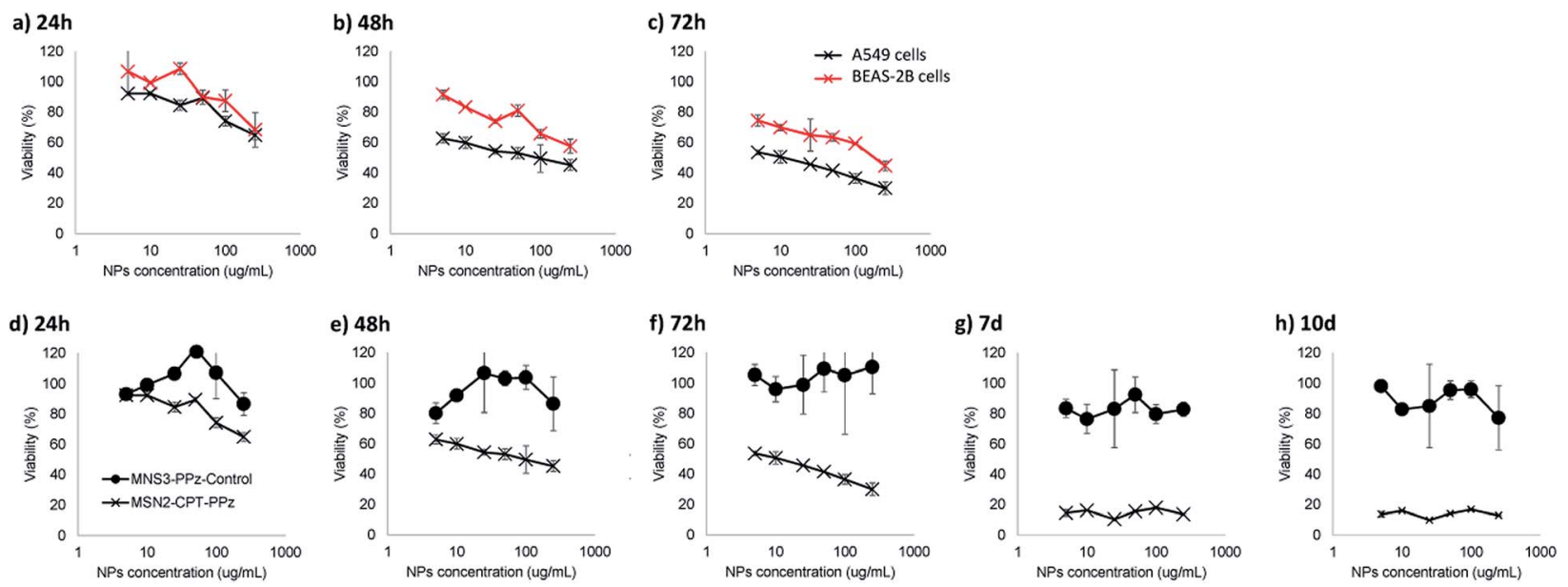

Fig. 6 In vitro viability studies based on MTT metabolic assays of: (a), (b) and (c) MSN2-CPT-PPz incubated with lung epithelial (BEAS-2B) and lung tumor (A549) cells, for different times, from (d) to (h) MSN3-PPz-control and MSN2-CPT-PPz nanoparticles incubated with A549 lung tumor cells.

that MSN2-CPT-PPz cytotoxicity was cell-type dependent. In a further study to confirm that toxicity came from the active drug (camptothecin) and not from the material used as the carrier, we also compared the lung cancer cells viability after their incubation with MSN2-CPT-PPz and with MSN3-PPzcontrol nanoparticles during different times. As it is clearly plotted in Fig. 6d-h, non-loaded nanoparticles did not produce cytotoxicity in lung tumor cells up to 10 days. Therefore, the cytotoxic effect was attributed directly to the encapsulated chemotherapeutic drug.

\section{Experimental}

\subsection{Chemicals}

Safranin O ( $\geq 85 \%)$, sodium ascorbate (99\%), tetraethyl orthosilicate (TEOS, 98\%), lithium bis(trimethylsilyl)amide $\left(\mathrm{LiN}\left(\mathrm{SiMe}_{3}\right)_{2}, 97 \%\right)$, phosphorous trichloride $\left(\mathrm{PCl}_{3}, 99 \%\right)$, dichlorotriphenylphosphorane $\left(\mathrm{Ph}_{3} \mathrm{PCl}_{2}, 95 \%\right)$, were purchased from Sigma Aldrich. Cetyltrimethylammonium bromide (CTAB, $>99 \%)$ was purchased from VWR. Triethylamine $\left(\mathrm{Et}_{3} \mathrm{~N}\right)$ from Merck was distilled and dried over molecular sieves (3 $\AA$ ). Sodium hydroxide (98\%) and copper(II) sulfate pentahydrate $(98.5 \%)$ were purchased from J. T. Barker. 3-Azidopropyl triethoxysilane (97\%), camptothecin ( $>98 \%)$ and 2-propynylamine (97\%) were purchased from fluorochem. Polyetheramine copolymer (PEO-PPO- $\mathrm{NH}_{2}$ ), sold under trade name Jeffamine® $\mathrm{M}-2005$, with nominal molecular weight of $2000 \mathrm{~g} \mathrm{~mol}^{-1}$, was purchased from Huntsman Performance Products. Deuterated chloroform $\left(\mathrm{CDCl}_{3}\right),(99.8 \%$, Sigma Aldrich) was used for NMR measurements. Uranyless EM Stain (contrast stain solution for TEM) was purchased from EMS. Solvents were purchased from VWR and Alfa Aesar, and used as received if not stated otherwise. Anti-LAMP1 rabbit primary antibody and goat anti-rabbit secondary antibody IgG H\&L (Alexa Fluor ${ }^{\circledR} 488$ ) were purchased from Abcam. DAPI was purchased from Sigma-Aldrich.

\subsection{Cell lines}

A549 (ATCC CCL-185) and BEAS-2B (ATCC CRL-9609) cell lines were maintained in DMEM supplemented with $10 \%(\mathrm{v} / \mathrm{v})$ heat inactivated fetal bovine serum (FBS, research grade, HyClone ${ }^{\mathrm{TM}}$ ), 100 units $\mathrm{mL}^{-1}$ penicillin $\mathrm{G}, 100 \mu \mathrm{g} \mathrm{mL} \mathrm{m}^{-1}$ streptomycin, and $2 \mathrm{mmol} \mathrm{L}^{-1} \mathrm{~L}$-glutamine. All cells were cultured at $37{ }^{\circ} \mathrm{C}$, under a $5 \% \mathrm{CO}_{2} / 95 \%$ air atmosphere until $90 \%$ confluence before starting transfections.

\subsection{Characterization techniques}

${ }^{1} \mathrm{H}$-NMR and ${ }^{31} \mathrm{P}$-NMR spectra were recorded with 300 and 121 $\mathrm{MHz}$, respectively, using a Bruker® Advance 300 spectrometer. $18 \mathrm{M} \Omega$ ultra pure water (Milli-Q water) was obtained from Millipore device with a Millipak® express 40 filter $(0.22 \mu \mathrm{m}$ pore size). BET-data were obtained from a TriStar II 3020 V1.01 was employed with $\mathrm{N}_{2}$ as adsorptive in an analysis bath at $77.30 \mathrm{~K}$. Thermogravimetric analyses were carried out with a TGA/ PerkinElmer Q5000, with platinum pans and measurements between 50 and $900{ }^{\circ} \mathrm{C}$, heating rate of $10{ }^{\circ} \mathrm{C} \mathrm{min}^{-1}$ under nitrogen $\left(25 \mathrm{~mL} \mathrm{~min}^{-1}\right)$. Transmission electron microscopy (TEM) images were obtained and elemental mapping analyses (TEM-EDX) were performed with a Jeol JEM-2200FS microscope at $200 \mathrm{kV}$. For TEM samples preparation, Milli-Q was used as dispersant $\left(0.1 \mathrm{mg} \mathrm{mL}^{-1}\right)$, and sonication for 15 minutes to disperse the sample. Nanoparticles were placed on 300 mesh copper grids coated with a holey carbon film. High-resolution TEM images were recorded by means of zero-loss filtering, using an in-column $\Omega$-filter. A Zetasizer Nano ZSP (Malvern Instruments) was used to obtain the hydrodynamic diameter $\left(D_{\mathrm{h}}\right)$ and zeta potential, by dynamic light scattering (DLS) of nanoparticles in Milli-Q water $\left(1 \mathrm{mg} \mathrm{mL}{ }^{-1}\right)$. For each measurement, 6 runs were performed. Lower critical solution temperatures (LCST) were determined by monitoring the optical transmittance at $500 \mathrm{~nm}$ of $1 \mathrm{mg} \mathrm{mL}^{-1}$ of polymers in aqueous phosphate buffered solution (PBS, $\mathrm{pH} 7.4$ and 5.2) and acidic aqueous solution ( $\mathrm{pH} 3.0)$ at temperatures ranging from 
$10{ }^{\circ} \mathrm{C}$ to $45{ }^{\circ} \mathrm{C}\left(1{ }^{\circ} \mathrm{C} \min ^{-1}\right)$, using a Cary UV $100 \mathrm{UV}$-Visible spectrometer equipped with a temperature programmer. The LCST was determined at 50\% transmittance value (sudden slope change in the transmittance curve). UV-Vis spectra measurements were performed using a PerkinElmer Lambda 35 UV-Visible spectrometer.

\subsection{Synthesis}

3.4.1. Jeffamine-based polyphosphazene (PPz). In a first step, the precursor poly(dichloro)phosphazene $\left[\mathrm{NPCl}_{2}\right]_{n}(n \sim 50)$ was prepared, according to phosphine-mediated polymerization already reported by our group. ${ }^{31}$ Dichlorotriphenylphosphorane (43.8 $\mathrm{mg}, 0.13 \mathrm{mmol}, 1$ eq.) was dissolved in anhydrous DCM $(0.5 \mathrm{~mL})$ and mixed with a solution of $\mathrm{Cl}_{3} \mathrm{P}=\mathrm{N}-\mathrm{SiMe}_{3}(1.68 \mathrm{~g}, 6.30 \mathrm{mmol}, 50 \mathrm{eq}$.) in anhydrous DCM $(0.5 \mathrm{~mL})$, stirred for $24 \mathrm{~h}$ in a glovebox. This polymer solution was used directly in the next step reaction without further purification. In a second step, the macromolecular substitution was started by adding $\mathrm{Et}_{3} \mathrm{~N}(0.44 \mathrm{~mL}, 3.16 \mathrm{mmol})$ and 2-propynylamine $(0.21 \mathrm{~mL}, 3.16 \mathrm{mmol})$ in THF $(2 \mathrm{~mL})$ dropwise to the previously synthetized polymer solution. The solution was stirred for $24 \mathrm{~h}$ at room temperature. Then, more $^{\mathrm{Et}}{ }_{3} \mathrm{~N}(0.9 \mathrm{~mL}, 6.46$ $\mathrm{mmol})$ and Jeffamine ${ }^{\circledR} \mathrm{M}-2005(12.61 \mathrm{~g}, 6.31 \mathrm{mmol})$ dissolved in THF (10 mL) were added. After $24 \mathrm{~h}, 2$-propynylamine $(1 \mathrm{~mL}$, $15.61 \mathrm{mmol})$ and $\mathrm{Et}_{3} \mathrm{~N}(2.2 \mathrm{~mL}, 15.78 \mathrm{mmol})$ were added in excess. Once the complete substitution of all chlorine atoms was confirmed by ${ }^{31} \mathrm{P}$ NMR spectroscopy, the polymer solution was filtered and the solvent removed under vacuum. The polymer was first purified in ice water and in cooled EtOH for $24 \mathrm{~h}$ each (dialysis membranes 6-8 kDa cut-off), and then again for $120 \mathrm{~h}$ in ice water (12-14 kDa cut-off). Afterwards, the water was removed by evaporation under vacuum, and further dried to yield a viscous liquid polymer $\mathrm{PPz}(6.22 \mathrm{~g}, 46.9 \%$, ratio Jeffamine ${ }^{\circledR} \mathrm{M}-2005:$ 2-propynylamine $\left.1: 2\right) .{ }^{1} \mathrm{H}$ NMR $(300 \mathrm{MHz}$, $\left.\mathrm{CDCl}_{3}, \delta\right): 3.35-3.62\left(108 \mathrm{H},-\mathrm{OCH}_{2},-\mathrm{CH}_{2}-\mathrm{C} \equiv \mathrm{C}\right), 2.22(\mathrm{~s}, 2 \mathrm{H}$, $\mathrm{CH} \equiv \mathrm{C}-), 1.10$ (m, 87H, $-\mathrm{CH}_{3}$ of PPO) ppm; ${ }^{31} \mathrm{P}$ NMR $(121 \mathrm{MHz}$, $\left.\mathrm{CDCl}_{3}, \delta / \mathrm{ppm}\right): 0.07\left(-\mathrm{N}=\mathrm{PR}_{2}-\right), 17.70\left(-\mathrm{N}=\mathrm{PPh}_{3}\right) \mathrm{ppm}$.

3.4.2. Mesoporous silica nanoparticles (MSNo). The synthetic procedure to prepare mesoporous silica nanoparticles (MSNs) was followed according with previous reports. ${ }^{33}$ Surfactant CTAB ( $1 \mathrm{~g}, 2.74 \mathrm{mmol})$ was dissolved in $480 \mathrm{~mL}$ of pure water, followed by the addition of $\mathrm{NaOH}(3.5 \mathrm{~mL}, 2 \mathrm{M})$. Then, TEOS (5 mL, $22.4 \mathrm{mmol}$ ) was added dropwise to the surfactant mixture at $80^{\circ} \mathrm{C}$ while stirring. After $2 \mathrm{~h}$, the white precipitated obtained was isolated by centrifugation and washed vigorously with deionized water until neutral $\mathrm{pH}$. The as-synthesized nanoparticles were dried at $60{ }^{\circ} \mathrm{C}$ for $12 \mathrm{~h}$ and finally, the surfactant was removed by calcination at $550{ }^{\circ} \mathrm{C}$ for $5 \mathrm{~h}$ obtaining the calcined white powder-like material MSN0.

3.4.3. Azide-functionalized mesoporous silica nanoparticles loaded with safranin O (MSN1-SAF-AZ). Safranin O (100 $\mathrm{mg}, 0.29 \mathrm{mmol}$ ) and previously calcined mesoporous silica nanoparticles MSN0 (350 mg) were suspended in $\mathrm{CH}_{3} \mathrm{CN}$ (35 $\mathrm{mL}$ ). Then, the suspension was heated to $110{ }^{\circ} \mathrm{C}$ to remove adsorbed water $(10 \mathrm{~mL})$ by azeotropic distillation under nitrogen atmosphere using a Dean-Stark set-up. After stirring the mixture for $24 \mathrm{~h}$ at room temperature, 3-azidopropyltriethoxysilane $(0.4 \mathrm{~mL}, 1.5 \mathrm{mmol})$ was added and the mixture stirred for another $6 \mathrm{~h}$. The resulting mixture was centrifuged and washed with $\mathrm{CH}_{3} \mathrm{CN}(12 \mathrm{~mL} \times 2)$. The final nanoparticles were dried at $40{ }^{\circ} \mathrm{C}$ in a vacuum oven for $12 \mathrm{~h}$, yielding to MSN1SAF-AZ as red powder-like material.

3.4.4. PPz-functionalized mesoporous silica nanoparticles loaded with safranin O (MSN1-SAF-PPz). With the aim of attaching the Jeffamine-based polyphosphazene via azidealkyne Huisgen cycloaddition, the material MSN1-SAF-AZ (100 $\mathrm{mg}$ ) was dispersed in DMSO : $\mathrm{H}_{2} \mathrm{O}$ mixture ( $5 \mathrm{~mL}: 4.75 \mathrm{~mL}$ ) and sodium ascorbate ( $4 \mathrm{mg}$ ) and $\mathrm{CuSO}_{4} \cdot 5 \mathrm{H}_{2} \mathrm{O}$ aqueous solution (20 $\mu \mathrm{L}, 1 \mathrm{mM})$ were added. Afterwards, the polymer was added

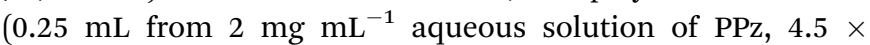
$10^{-9} \mathrm{~mol}$, equal to $0.4 \mathrm{eq}$. of corresponding triple bonds) leading to a $1: 1$ ratio of both solvents, and the reaction mixture was stirred for $24 \mathrm{~h}$ at room temperature. Finally, the resulting nanoparticles were centrifuged and washed with $\mathrm{H}_{2} \mathrm{O}(15 \mathrm{~mL} \times$ 4) and $\mathrm{CH}_{3} \mathrm{CN}(15 \mathrm{~mL} \times 2)$ and dried under vacuum at $35^{\circ} \mathrm{C}$ for $12 \mathrm{~h}$, to yield the pink-red powder MSN1-SAF-PPz.

3.4.5. Azide grafted mesoporous silica nanoparticles loaded with anticancer drug camptothecin (MSN2-CPT-AZ). Cytotoxic drug camptothecin $(140 \mathrm{mg}, 0.40 \mathrm{mmol})$ and previously calcined mesoporous silica nanoparticles MSN0 (250 mg) were suspended in $\mathrm{CH}_{3} \mathrm{CN}: \mathrm{MeOH}(1: 1,60 \mathrm{~mL})$ under nitrogen atmosphere. After stirring the mixture for $24 \mathrm{~h}$ at room temperature, 3-azidopropyltriethoxysilane $(0.27 \mathrm{~mL}, 1.1 \mathrm{mmol})$ was added and the mixture stirred for another $6 \mathrm{~h}$. The resulting mixture was centrifuged and washed with $\mathrm{CH}_{3} \mathrm{CN}(10 \mathrm{~mL} \times 2)$. The final nanoparticles MSN2-CPT-AZ were dried under vacuum at $35{ }^{\circ} \mathrm{C}$ for $12 \mathrm{~h}$, as yellowish powder material.

3.4.6. Synthesis of PPz grafted nanoparticles loaded with anticancer drug camptothecin (MSN2-CPT-PPz). Following same procedure as for preparing MSN1-SAF-PPz, the material MSN2-CPT-AZ (100 mg) was dispersed in DMSO : $\mathrm{H}_{2} \mathrm{O}$ (5 $\mathrm{mL}: 4.75 \mathrm{~mL}$ ) and sodium ascorbate $(4 \mathrm{mg})$ and $\mathrm{CuSO}_{4} \cdot 5 \mathrm{H}_{2} \mathrm{O}$ aqueous solution $(20 \mu \mathrm{L}, 1 \mathrm{mM})$ were added. Afterwards, the polymer was added $\left(0.25 \mathrm{~mL}\right.$ from $2 \mathrm{mg} \mathrm{mL}^{-1}$ aqueous solution of $\mathrm{PPz}, 4.5 \times 10^{-9} \mathrm{~mol}$, equal to $0.4 \mathrm{eq}$. of corresponding triple bonds), leading to a $1: 1$ ratio of both solvents, and the reaction mixture was stirred for $24 \mathrm{~h}$ at room temperature. Finally, the resulting nanoparticles were centrifuged and washed with $\mathrm{H}_{2} \mathrm{O}$ $(15 \mathrm{~mL} \times 4)$ and $\mathrm{CH}_{3} \mathrm{CN}(15 \mathrm{~mL} \times 2)$ and dried under vacuum at $35{ }^{\circ} \mathrm{C}$ for $12 \mathrm{~h}$, obtaining MSN2-CPT-PPz as yellowish powderlike material.

3.4.7. Synthesis of non-loaded nanoparticles functionalized with PPz (MSN3-PPz-control). An extra material was prepared following the same procedure as for nanoparticles MSN2-CPT-PPz but without any cargo, grafting PPz on the silica surface, yielding to white powder-like material MSN3-PPzcontrol.

\subsection{Cargo release studies}

In a typical release experiment, prepared solid MSN1-SAF-PPz (5 $\mathrm{mg}$ ) was suspended in $12.5 \mathrm{~mL}$ of PBS solutions at $\mathrm{pH} 7.4$ and $\mathrm{pH} 5.2$, and acidic solution of $\mathrm{pH}$. Aliquots of $1 \mathrm{~mL}$ were 
collected and filtered (to remove the nanoparticles) at certain times during $24 \mathrm{~h}$. The absorbance of safranin $\mathrm{O}$ at $520 \mathrm{~nm}$ was measured for $24 \mathrm{~h}$ (1440 min). Partial dye release studies were also followed only with MSN1-SAF-PPz nanoparticles, as a function of temperature variation at $5{ }^{\circ} \mathrm{C}(<\mathrm{LCST})$ and at $37{ }^{\circ} \mathrm{C}$ (>LCST). For this experiment, $5 \mathrm{mg}$ of nanoparticles were suspended in $12.5 \mathrm{~mL}$ of PBS at $\mathrm{pH} 7.4$ and stirred for $24 \mathrm{~h}$, while aliquots of $1.0 \mathrm{~mL}$ were collected and centrifuged. The absorbance of safranin $\mathrm{O}$ was measured at $520 \mathrm{~nm}$. After $24 \mathrm{~h}$, the temperature was increased to $37^{\circ} \mathrm{C}$. The same samples collecting and measuring procedure was followed for $48 \mathrm{~h}$. The whole experiment was performed over $72 \mathrm{~h}$ in total.

\subsection{Nanoparticles cellular uptake studies}

Cells were seeded either in a 96-well plate or in glass copper slices placed in a 6 -well plate, previously coated with $0.1 \%$ gelatin solution, at $90 \%$ confluence, $24 \mathrm{~h}$ before starting the experiment. MSN1-SAF-PPz was incubated with cells for different experimental times, to determine cell uptake. Nanoparticles uptake, using safranin as reporter $\left(\lambda_{\text {excitation }}=532 \mathrm{~nm}\right.$; $\lambda_{\text {emission }}=560 \mathrm{~nm}$ ), were determined. Qualitative studies were carried out by Leica TCS SP8 laser-scanning confocal spectral microscope (Leica Microsystems Heidelberg, Mannheim, Germany) with Argon and HeNe lasers attached to a Leica DMi8 S Platform inverted microscope. For visualization of the nanoparticles uptake, images were acquired using an APO $40 \times$ objective lens. Numerical aperture 1.4, 405, 488 and $528 \mathrm{~nm}$ laser lines, acoustic beam splitter, emission detected in the range of 410-430, 500-520, 535-580 and the confocal pinhole set at 1 Airy units. Nuclei were stained by 5 min incubation with DAPI. Immunofluorescence was performed to label lysosomes through LAMP1 staining and further mounting the copper slices in a glass slide. Flow cytometry (NovoCyte, ACEA Bioscience) was used to quantify uptake efficiency. Briefly, at the end of the experiment, cells were trypsinized and fixed with $1 \%$ paraformaldehyde. At least 2000 cells were analyzed for each well. Results correspond to the mean \pm standard deviation of at least three independent experiments, each consisting on an experiment triplicate.

\subsection{In vitro viability studies}

Cells were seeded in a 96-well plate at $90 \%$ confluence, $24 \mathrm{~h}$ before starting the experiment. Cells were incubated with increasing amounts of the different kinds of nanoparticles tested, at increasing concentrations. Non-treated cells were used as negative controls ( $100 \%$ viability). In vitro cell viability was evaluated through quantification of cell metabolic activity, by using MTT colorimetric assay. Briefly, nanoparticles were incubated for $48 \mathrm{~h}$ with cells. After this time, media were removed and replaced with $0.5 \mathrm{mg} \mathrm{mL}^{-1}$ MTT in complete media and further incubated for around $3 \mathrm{~h}$. Following, media were removed and formazan crystals were dissolved in $100 \mathrm{~mL}$ DMSO. Absorbance was quantified at $570 \mathrm{~nm}$, using a plate reader (SpectraMax M5, Molecular Devices). Results are expressed as percentage of viable cells related to non-treated cells (100\% viability).

\section{Conclusions}

We describe the use of $\mathrm{pH}$ and thermoresponsive bottle-brush polyphosphazenes as a gatekeeper for dual responsive mesoporous silica nanoparticles, designed to release the uploaded cargo at acidic $\mathrm{pH}$ conditions and body temperatures. A mesoporous silica nanomaterial MSN1-SAF-PPz was loaded with a selected dye (safranin O, SAF) as a model cargo and covalently decorated with azide units, to facilitate the subsequent functionalization with the $\mathrm{PPz}$ via azide-alkyne "click" reaction enabling the easy grafting to the silica pores outer surface. A detailed characterization was carried out to ensure the presence of the polymer on the nanoparticles, which was clearly verified. The potential close-open dual response mechanism of the gate hybrid nanosystem was demonstrated, showing negligible release at neutral $\mathrm{pH}$, related to healthy cells, and cold temperatures, which can be selectively opened, leading to rapid payload release under acidic conditions at body temperature (typical of cancer cells). The same type of mesoporous silica nanoparticles functionalized with PPz but not loaded (MSN3PPz-control) were tested showing positive high biocompatibility, which could open up the potential use in vitro and in vivo. Therefore, the possible bioapplication of the gated system for on demand controlled delivery of lung cancer treatments was directly translated to in vitro studies by the preparation of the same formulation but loaded with chemotherapeutic drug camptothecin, CPT (nanomaterial MSN2-CPT-PPz). We demonstrated that these nanoparticles were able to penetrate cells both tumor and healthy cells, being their toxic effects more pronounced in tumor cells. In addition, it became clear by confocal microscopy that they accumulate in lysosomes, which is an advantageous point for their further use for lysosome targeting and in terms of avoiding toxicity due to accumulation. This was confirmed by the selective cytotoxicity produced only in lung tumor models when camptothecin was encapsulated as a model chemotherapeutic drug in MSN capped with PPz. In summary, we have demonstrated that a novel MSN formulation, based on a biocompatible $\mathrm{pH}$ and temperature responsive polyphosphazene-based molecular gate, is able to produce a selective, concentration and time-dependent toxicity to lung tumor cell models when camptothecin is encapsulated. This works brings up the possibility of using a wide range of responsive units onto the polyphosphazene backbone designed for specific release applications, such as controlled antitumor therapeutics, based on gated silica mesoporous nanosystems.

\section{Conflicts of interest}

There are no conflicts to declare.

\section{Acknowledgements}

Y. S. and I. T. express their gratitude to the Linz Institute of Technology, Johannes Kepler University at Linz, and the State of Upper Austria (Project LIT 213760001 DEG-PMO) for the funding. C. F. and S. B. acknowledge Agència de Gestió d'Ajuts Universitaris i de Recerca (AGAUR) de la Generalitat de 
Catalunya for the grant SGR 1551 to the Grup d'Enginyeria de Materials (GEMAT) and the Spanish Ministerio de Ciencia, Innovación y Universidades for the grant RTI2018-094734-BC22. NMR experiments were performed at the Upper Austrian-South Bohemian Research Infrastructure Center in Linz, co-financed by "RERI-uasb", EFRE RU2-EU-124/100-2010 (ETC Austria-Czech Republic 2007-2013, Project M00146). Authors also acknowledge $\mathrm{P}$. Oberhumer from centre for nano-and surface analytics (ZONA) for the TEM measurements and the Institute for Organic Chemistry for the access to the UV-Vis Cary spectrometer. Publication funded by the Johannes Kepler Open Access Publishing Fund.

\section{References}

1 D. Roy, J. N. Cambre and B. S. Sumerlin, Prog. Polym. Sci., 2010, 35, 278-301.

2 G. Martínez-Edo, M. C. Llinàs, S. Borrós and D. SánchezGarcía, Nanomaterials, 2019, 9(1-16), 1219.

3 M. C. Llinàs, G. Martínez-Edo, A. Cascante, I. Porcar, S. Borrós and D. Sánchez-García, Drug Delivery, 2018, 25, 1137-1146.

4 J. Hu and S. Liu, Macromolecules, 2010, 43, 8315-8330.

5 L. D. Zarzar and J. Aizenberg, Acc. Chem. Res., 2014, 47, 530539.

6 M. Talelli, A. Duro-Castaño and G. Rodríguez-Escalona, Smart polymer nanocarriers for drug delivery, ed. M. J. Vicent, Woodhead Publishing, 2014, pp. 327-358.

7 I. Teasdale, Eur. J. Inorg. Chem., 2019, 1445-1456.

8 S. Rothemund and I. Teasdale, Chem. Soc. Rev., 2016, 45, 5200-5215.

9 I. Teasdale and O. Brüggemann, Polyphosphazenes for medical applications, Smithers Rapra, Shrewsbury, UK, 2014.

10 H. R. Allcock and N. L. Morozowich, Polym. Chem., 2012, 3, 578-590.

11 M. C. Bates, A. Yousaf, L. Sun, M. Barakat and A. Kueller, Regener. Eng. Transl. Med., 2019, 5, 341-353.

12 A. K. Andrianov, D. P. DeCollibus, H. A. Gillis, H. H. Kha, A. Marin, M. R. Prausnitz, L. A. Babiuk, H. Townsend and G. Mutwiri, Proc. Natl. Acad. Sci. U. S. A., 2009, 106, 1893618941.

13 A. K. Andrianov, Polyphosphazenes for biomedical applications, John Wiley \& Sons, Inc., 2006, pp. 355-378.

14 K. H. Hong, Y.-M. Kim and S.-C. Song, Adv. Sci., 2019, 6, 1900597.

15 Z.-Q. Zhang and S.-C. Song, Biomaterials, 2017, 132, 16-27.

16 D. Roy, W. L. A. Brooks and B. S. Sumerlin, Chem. Soc. Rev., 2013, 42, 7214-7243.

17 Q. Zhang, C. Weber, U. S. Schubert and R. Hoogenboom, Mater. Horiz., 2017, 4, 109-116.

18 X. Gao, N. Kučerka, M.-P. Nieh, J. Katsaras, S. Zhu, J. L. Brash and H. Sheardown, Langmuir, 2009, 25, 10271-10278.

19 M. Kneidinger, A. Iturmendi, C. Ulbricht, T. Truglas, H. Groiss, I. Teasdale and Y. Salinas, Macromol. Rapid Commun., 2019, 40, 1900328.
20 K. Nagase, M. Yamato, H. Kanazawa and T. Okano, Biomaterials, 2018, 153, 27-48.

21 S. Wilfert, A. Iturmendi, H. Henke, O. Brüggemann and I. Teasdale, Macromol. Symp., 2014, 337, 116-123.

22 G. Vancoillie, D. Frank and R. Hoogenboom, Prog. Polym. Sci., 2014, 39, 1074-1095.

23 T. V. Burova, V. Y. Grinberg, N. V. Grinberg, A. S. Dubovik, A. P. Moskalets, V. S. Papkov and A. R. Khokhlov, Macromolecules, 2018, 51, 7964-7973.

24 S. Giret, M. W. Chi Man and C. Carcel, Chem.-Eur. J., 2015, 21, 13850-13865.

25 Z. Li, J. C. Barnes, A. Bosoy, J. F. Stoddart and J. I. Zink, Chem. Soc. Rev., 2012, 41, 2590-2605.

26 E. Aznar, M. Oroval, L. Pascual, J. R. Murguia, R. MartinezManez and F. Sancenon, Chem. Rev., 2016, 116, 561-718.

27 A. García-Fernández, E. Aznar, R. Martínez-Máñez and F. Sancenón, Small, 2020, 16, 1902242.

28 Y. Salinas, R. Martinez-Manez, J. O. Jeppesen, L. H. Petersen, F. Sancenón, M. D. Marcos, J. Soto, C. Guillem and P. Amoros, ACS Appl. Mater. Interfaces, 2013, 5, 1538-1543.

29 C. T. Kresge, M. E. Leonowicz, W. J. Roth, J. C. Vartuli and J. S. Beck, Nature, 1992, 359, 710-712.

30 H. C. Kolb, M. G. Finn and K. B. Sharpless, Angew. Chem., Int. Ed., 2001, 40, 2004-2021.

31 S. Wilfert, H. Henke, W. Schoefberger, O. Brüggemann and I. Teasdale, Macromol. Rapid Commun., 2014, 35, 1135-1141. 32 K. Sarkar, Y. Salinas, I. Campos, R. Martinez-Manez, M. D. Marcos, F. Sancenón and P. Amorós, ChemPlusChem, 2013, 78, 684-694.

33 Y. Salinas, C. Hoerhager, A. Garcia-Fernandez, M. Resmini, F. Sancenon, R. Martinez Manez and O. Brueggemann, ACS Appl. Mater. Interfaces, 2018, 10, 34029-34038.

34 I. Candel, E. Aznar, L. Mondragon, C. De La Torre, R. Martínez-Máñez, F. Sancenon, M. D. Marcos, P. Amoros, C. Guillem, E. Perez-Paya, A. Costero, S. Gil and M. Parra, Nanoscale, 2012, 4, 7237-7245.

35 E. Aznar, M. D. Marcos, R. Martinez-Manez, F. Sancenon, J. Soto, P. Amoros and C. Guillem, J. Am. Chem. Soc., 2009, 131, 6833-6843.

36 A. Wicki, D. Witzigmann, V. Balasubramanian and J. Huwyler, J. Controlled Release, 2015, 200, 138-157.

37 V. Y. Grinberg, T. V. Burova, N. V. Grinberg, V. S. Papkov, A. S. Dubovik and A. R. Khokhlov, Journal of Physical Chemistry B, 2018, 122, 1981-1991.

38 A. Bernardos, L. Mondragón, I. Javakjhishvili, N. Mas, C. De la Torre, R. Martinez-Manez, F. Sancenon, J. M. Barat, S. Hvilsted, M. Orzaez, E. Perez-Paya and P. Amoros, Chem.-Eur. J., 2012, 18, 13068-13078.

39 R. Duncan and S. C. W. Richardson, Mol. Pharmaceutics, 2012, 9, 2380-2402.

40 R. Boustany, Nat. Rev. Neurol., 2013, 9, 583-598. 